\title{
Subacute bacterial endocarditis (SBE) due to Streptococcus gordonii
}

Raffaella Battista, Adriana Raddi, Francesco Labonia, Marcello Raffone, Alessia Sommella, Marina Pedicelli, Michele Di Cecio, Riccardo Smeraglia

U.O.C. Microbiologia e Virologia, A.O.R.N. “V. Monaldi”- Napoli

Key words: Streptococcus gordonii, Endocarditis, Blood coltures

Endocardite batterica subacuta (EBS) causata da Streptococcus gordonii

SUMMARY

Endocarditis is an inflammatory state of the endothelium that promotes thrombus formation and tissue damage on the surface of heart valves. Recent studies have reported endocarditis mortality rates ranging from $12 \%$ to $46 \%$ (2008). The Streptococcus gordonii is a normal inhabitant of the human oral cavity. It is a component of the microbial communities responsible of plaque formation, associated with dental caries and also regarded as the main causative agent in the development of subacute bacterial endocarditis (SBE).

L'Endocardite è un processo infiammatorio dell'endotelio che riveste la superficie interna della cavità del cuore (l'endocardio) soprattutto localizzato a livello delle valvole cardiache generalmente conseguente ad un'infezione.

Esistono diversi tipi di endocardite: quella batterica subacuta, quella batterica acuta, quella micotica e quella non infettiva. Recenti studi hanno riportato tassi di mortalità per endocardite che vanno dal $12 \%$ al $46 \%$ (2008) (1).

L'endocardite batterica subacuta (EBS) è di solito causata da varie specie di streptococchi, in particolare streptococchi viridanti, microaerofili e anaerobi, S. bovis, non-enterococchi di Gruppo D ed enterococchi, e, meno frequentemente, da Staphylococcus aureus, S. epidermidis e da Haemophilus spp. Lo S. gordonii è un membro della famiglia degli streptococchi viridanti, $\alpha$-emolitico, appartenente al gruppo dello $S$. sanguinis (6), inizialmente incluso nel gruppo dello $S$. mitis (5). Lo S. gordonii è un batterio considerato un saprofita della microflora orale. Questo colonizzatore primario svolge una funzione necessaria per la creazione di comunità microbiche che sono caratteristiche della placca dentale, noto comunemente per essere associato allo sviluppo della carie dentaria, anche considerato come uno degli agenti eziologici dell'Endocardite Batterica Subacuta (EBS). Quando è presente una lesione sull'endocardio o più frequentemente su una delle valvole cardiache, la fibrina e le piastrine aderiscono alla superficie dell'endocardio, formando un trombo sterile, definito vegetazione, che rende poi la parte sensibile alla colonizzazione da parte di microrganismi, che guadagnano così l'accesso al flusso sanguigno attraverso microlesioni del tessuto orale indotte da traumi provocati da manipolazioni dentarie, procedure per l'igiene dentale, masticazione ed infezione del cavo orale (4). Questi microrganismi contengono molte proteine di superficie che facilitano l'adesione sia della vegetazione che di ulteriori piastrine circolanti, in modo da intrappolare il batterio all'interno del reticolo di vegetazione (3).

\section{CASO CLINICO}

Nel maggio 2009 è stato ricoverato nel reparto di Medicina Infettivologica dell'A.O.R.N. "V. Monaldi" un uomo di 32 anni affetto da una valvulopatia congenita della valvola bicuspide, che presentava malessere ed un rialzo della temperatura pari a $39^{\circ} \mathrm{C}$. Sul paziente in oggetto sono state effettuate analisi chimiche con prelievi nell'arco di 15 giorni. L'emocromo aveva evidenziato un lieve aumento nella percentuale dei neutrofili $(73 \%)$ ed una riduzione dei valori di HCT $(40 \%)$ e di MCHC (35 g/dl). L'esame delle urine evidenziava tracce di emoglobina ed i valori del fibrinogeno erano superiori ai limiti stabiliti $(413 \mathrm{mg} / \mathrm{dL})$. Inoltre il quadro proteico elettroforetico mostrava un leggero aumento delle globuline $\alpha 1$ e si constatava un aumento della proteina $\mathrm{C}$ reattiva a conferma della presenza di un'infezione o di uno stato infiammatorio in atto. L'anamnesi, inoltre, aveva evidenziato che il soggetto nell'anno precedente al ricovero, si era sottoposto a cure dentarie; per cui tutti i sintomi facevano sospettare un'endocardite batterica.

Per isolare l'agente eziologico è stato sufficiente utilizzare un test standard per diagnosticare episodi di batteriemia quale l'emocoltura. Nel nostro laboratorio di microbiologia, il protocollo per il trattamento delle emocolture prevede che il sangue arrivi in laboratorio nei flaconi Bactec $(8-10 \mathrm{ml})$ aerobi, anaerobi o pediatrici che contengono brodo di arricchimento, resine a cui aderiscono eventuali residui di antibiotici in circolo ed un substrato cromogeno, in grado di colorarsi e di emettere fluorescenza in presenza di anidride carbonica, principale catabolita del metabolismo batterico; in genere, per isolare l'agente eziologico, sono sufficienti 3/4 emocolture nelle $24 \mathrm{~h}$ eseguite ogni 30 minuti al picco febbrile. Di questo paziente, sono pervenute 4 emocolture per la ricerca di microrganismi aerobi ed anaerobi; i flaconi sono stati incubati nell'apparecchio BACTEC 9120 (Becton-Dickinson). Normalmente le emocolture vengono incubate per 7 giorni ma nei casi di sospetta endocardite l'incubazione si protrae per 21 giorni.

Quelle risultate positive sono state processate secondo il nostro protocollo operativo: si procede prelevando del materiale su cui si effettua una prima osservazione al microscopio eseguendo la colorazione di Gram dei preparati e la semina su Agar sangue, e sugli altri terreni selettivi (Agar CNA, Agar MacConkey, Agar Sabouraud con Cloramfenicolo, Agar Pseudosel, Agar Mannite, Agar Enterococco e su indicazione microscopica terreni cromogeni quali MRSA, ESBL o VRE per evidenziare tempestivamente ceppi sentinella).

L'osservazione diretta effettuata attraverso la colorazione di Gram, ha permesso di evidenziare nel campione la presenza di cocchi Gram positivi disposti a catenelle.

Nelle successive 24h le piastre di Agar sangue e Agar CNA incubate a $37^{\circ} \mathrm{C}$ ad un'atmosfera del $10 \%$ di $\mathrm{CO}_{2}$, presentavano una crescita di streptococchi $\alpha$-emolitici. È stato utilizzato il sistema API Rapid32Strep (bioMérieux) con il quale è possibile identificare in $4 \mathrm{~h}$ la maggior parte degli streptococchi (2). La nostra analisi ha mostrato che il microrganismo responsabile della patologia era uno $S$. gordonii.

Contemporaneamente è stato allestito il test per la valutazione della sensibilità agli antimicrobici. È stato utilizzato il sistema ATB Strep (bioMérieux); un sistema semiautomatico che ha rilevato, per il ceppo isolato, una resistenza alle cefalosporine di terza generazione (cefotaxime), ai macrolidi (eritromicina), ai lincosamidi (clindamicina), ed alle cicline (tetracicline); una sensibilità ai chinoloni di terza generazio-

\section{Corresponding author: Raffaella Battista}

A.O.R.N."V. Monaldi" - Napoli,Via Leonardo Bianchi - Tel.: 08I 70624I8 - Fax: 08 I 7064250

E-mail: raffaella.battista@ospedalemonaldi.it 
ne (levofloxacina), ai fenoli (cloramfenicolo), ed ai glicopeptidi (vancomicina); ed è risultato intermedio alla penicillina (Tabella 1).

Tabella I. Schema degli antimicrobici testati per lo S. gordonii

\begin{tabular}{lccc}
\hline Antibiotici & Sensibile & Intermedio & Resistente \\
\hline Cefotaxime & & \\
\hline Eritromicina & & $\mathrm{X}$ \\
\hline Clindamicina & & $\mathrm{X}$ \\
\hline Tetraciclina & & $\mathrm{X}$ \\
\hline Penicillina & & $\mathrm{X}$ & \\
\hline Levofloxacina & $\mathrm{X}$ & & \\
\hline Cloramfenicolo & $\mathrm{X}$ & \\
\hline Vancomicina & $\mathrm{X}$ & & \\
\hline
\end{tabular}

L'endocardite batterica subacuta (EBS) è caratterizzata da un'infezione microbica dell'endocardio con un esordio che può mimare altre malattie sistemiche. Dal momento che i sintomi e i segni non sono specifici, ma sono molto variabili e possono essere insidiosi, se non trattati possono avere esito fatale: la diagnosi richiede un alto indice di sospetto. Il rischio è massimo in pazienti con storia di valvulopatia che si sono recentemente sottoposti a procedure diagnostico-terapeutiche invasive o interventi sull'arcata dentaria e nei tossi- codipendenti. La positività dell'emocoltura è un dato di laboratorio specifico necessario per identificare ed isolare il microrganismo. Diagnosticare la patologia precocemente identificando il microrganismo e la sua sensibilità agli antimicrobici è essenziale affinché la terapia risulti battericida e riduca il rischio di mortalità.

\section{BIBLIOGRAFIA}

1. Ge X, Kitten T, Chen Z, Lee SP, Munro CL, Xu P. Identification of Streptococcus sanguinis Genes Required for Biofilm Formation and Examination of Their Role in Endocarditis Virulence (2008).

2. Freney J, Bland S, Etienne J, Desmonceaux M, Boeufgras MJ, Fleurette J. Description and Evaluation of the Semiautomated. Journal Of Clinical Microbiology, 1992; Vol. 45: 2657-6.1

3. 4-Hour Rapid ID 32 Strep Method for Identification of Streptococci and Members of Related Genera.

4. Herzberg Platelet-streptococcal interactions in endocarditis.(1996) Crit Rev Oral Biol Med 7:222-236

5. Hurst JW, Schlant RC, Rackley CF, Sonnenblick EH, Wenger NK, editors. Infective and non infective endocarditis. New York: McGraw-Hill. $1990 ; 1230-55$.

6. Kawamura Y, Hou XG, Sultana F, Miura H, Ezaki T. Determination of $16 \mathrm{~s}$ rRNA Sequences of Streptococcus mitis and Streptococcus gordonii and Phylogenetic Relationships among Members of the Genus Streptococcus. International Journal of Systematic Bacteriology, 1995; 5: 406-8.

7. Standards Unit, Evaluations e Standards Laboratory. Identificazione di specie streptococcus, specie enterococcus e microrganismi morfologicamente simili. Centre for Infections. (BSOP ID 4) 